\title{
An Audiometric Survey of Royal Artillery Gun Crews Following "Operation Corporate"
}

\author{
Lt Col J Anderson \\ MBChB, MSc, RAMC \\ RAMC Training Group, Aldershot
}

SUMMARY: An Audiometric Survey was carried out on two batteries of 4 Fd Regt RA (n-84) who were exposed to massive levels of impulse noise during "OP CORPORATE". A control group (n-30) was obtained from the remaining battery which did not serve in the Falklands, and it was matched well in age, service and job.

They completed a questionnaire, were physically examined and had an audiogram using the MAICO M26 computer audiometer. Results were related to PULHEEMS standards and compared.

No subject in the control group was classed below $\mathrm{H2}$ but in those exposed, 17 were $\mathrm{H3}$ or worse. This is significant ( 0.01 for 1 df) but the significance is attenuated medically and statistically. No significant correlation was found between type of ear defender and degree of protection.

The survey showed that sufficient numbers had been affected to necessitate a full examination of all troope who fought in East Falkland.

\section{Introduction}

Noise Induced Hearing Loss (NIHL) has long been known as the result of repeated exposure to high levels of continuous noise, especially at work, being time related as regards exposure years and duration of each exposure.

The Armed Services are no exception to this problem, but have the additional complication of being exposed to high levels of impulse noise from assorted weaponry ${ }^{1}$, particularly in the Royal Artillery. One of the difficulties in determining the severity of impulse noise, has been in equating it to continuous noise levels. Aterley and Martin ${ }^{2}$ have devised a method of doing so using knowledge of peak levels (pressure), frequency rates and delay time constants of the noise waveform.

Separate papers by Livesey ${ }^{3}$ and Brasher ${ }^{4}$ have shown, within the Army, a significant number of soldiers were suffering from NIHL, without being aware of it, and these were particularly apparent in R.A. units. Studies into the effects of impulse noise on volunteers, limited ethically, showed that barotrauma to all structures in the ear and in particular the Organ of Corti could result in tinnitus and Temporary Threshold Shift (TTS) from impulsive noise 4 . In addition Brasher found that almost half of his exposed group were very 'sensitive' to impulse noise and were therefore in greater danger of suffering permanent damage. The tactical implications of having 'deaf' soldiers as sentries or wireless operators are obvious.

Among the Armed Services of other countries, the artillery also appears to be most at risk. Oro studying a mixed group of soldiers in Singapore Paul, Chai and Thomas ${ }^{5}$ found that of those witb NIHL, $26 \%$ were artillerymen.

At a result of these studies and others, the Armo Hearing Conservation Programme ${ }^{6}$ was formed to protect the Serviceman's hearing. The details are now well documented, but briefly, the main accent has been on personal protection of the man by ear defenders and routine audiometry. Group protection, where possible, has been attempted by sound monitoring measures laid down by the Health and Safety at Work Act $1974^{7}$ in conjunction with the 1972 Code of Practice ${ }^{8}$. These are now being updated and improvements are being achieved through a Consultative Document $1981^{9}$ which gives detailed advice on wearer protection.

From a Service viewpoint, such recommendations have been anticipated and are already in use, with regular audiometry being the main screening and monitoring test of an individual's hearing. New gradings in PULHEEMS standards have been introduced since 197910,11, and associated grades in decibels are shown in Table I. These grades refer to summated decibel loss in the $0.5,1,2 \mathrm{KHz}$ (low), and 3,4 and $6 \mathrm{KHz}$ (high) ranges. The " $\mathrm{H}$ " level for each ear is now given as in Table I; the 'worse' ear grading will determine any restriction placed in the soldiers' work capacity. Where there is a great deal of exposure to high noise levels, yearly audiometry is advised and the Royal Artillery fall into this category. 
Table I

New Joint Service Audiometrically Based Hearing Standards

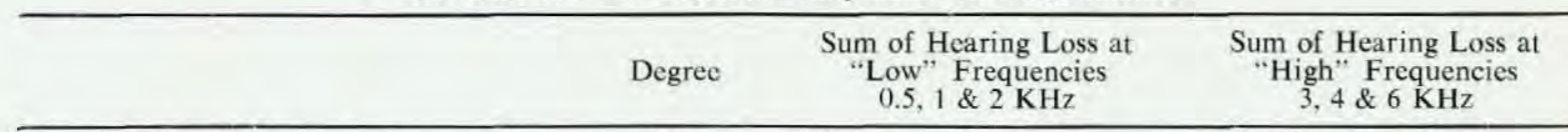

Compatible with $\mathrm{P} 1$ and $\mathrm{P} 2$.

$\mathrm{H} 2$ to remain minimum entry

standard to most Army employments

Limited flexibility to P2, P3,

P7 at the discretion of the

ENT specialist

Compatible with P7

Unfit for service P8
H1

$\mathrm{H} 2$

$\mathrm{H} 3$

H4 I

$\mathrm{H} 8$
Not more than $45 \mathrm{~dB}$

Not more than $84 \mathrm{~dB}$

Not more than $150 \mathrm{~dB}$

Greater than $150 \mathrm{~dB}$
Not more than $45 \mathrm{~dB}$

Not more than $123 \mathrm{~dB}$

Not more than $210 \mathrm{~dB}$

Greater than $210 \mathrm{~dB}$

\section{The Problem}

In 1982, the Falklands War broke out, and as a result, British troops were in active service on a scale not seen since the Fifties with Suez.

Modern weaponry has advanced to such a level that the impulse noise factor of many weapons is exceedingly high. Among one of the noisiest pieces is the $105 \mathrm{~mm} \mathrm{Fd}$ gun (Fig 1) used by field artillery units.

Tests $^{12}$ on this gun have shown that at maximum impulse charge (charge super) the impulse noise level is $185 \mathrm{~dB}(\mathrm{a})$ for a period of $20-25$ msecs. Since the gun has no shrapnel shield, the loader and the No 1 (Fig 1) as well as the limber men are all exposed to the maximum firing effect of the gun. Recommendations from the Army Personnel Research Establishment (APRE) are that all people exposed must wear ear defenders and, if necessary, both inserts and muffs together. The noise attenuations achieved by different types of ear defender are shown in Table II.

As part of routine gun drill, and in training for a North West Europe conflict, orders are given from command posts to the guns by wireless/

Table II

Noise Attenuation

\begin{tabular}{|c|c|c|c|c|}
\hline \multirow{2}{*}{$\begin{array}{l}\text { Octave band } \\
\text { centre frequency } \\
\mathrm{Hz}\end{array}$} & \multicolumn{4}{|c|}{$\begin{array}{c}\text { Attenuation Value } \\
\mathrm{dB}\end{array}$} \\
\hline & $\begin{array}{l}\text { V51R } \\
\text { Plug }\end{array}$ & Glass & Down & $\begin{array}{c}\text { Fluid Seal } \\
\text { Muff }\end{array}$ \\
\hline 63 & 11 & & & 17 \\
\hline 125 & 13 & & & 18 \\
\hline 250 & 15 & & 1 & 20 \\
\hline 500 & 18 & & 3 & 30 \\
\hline 1000 & 22 & & 6 & 38 \\
\hline 2000 & 27 & & 6 & 40 \\
\hline 4000 & 32 & & 3 & 43 \\
\hline 8000 & 29 & & & 35 \\
\hline
\end{tabular}

telephone links. These necessitate headsets whiclo are incorporated in ear muffs, for full protection $\frac{\dot{\omega}}{\omega}$ Soldiers who do not serve close to the guns or have no need for earphones are issued with the insern type of defender, the Sonex V51 plug.

In the event of wireless/telephone facilities bef? impracticable (as in the Falklands) shouted ord@् through megaphones or loudspeakers are given. Ts cosmocord ear defender is designed for this, bepp a muff type defender with hearing aids placed ins it. Orders are then amplified but any impulse nogie activates a baffle which disconnects the aid. लिछ्ष main drawbacks to these defenders are experse? the time taken to position them, the battery life the hearing aid inserted and the soldier abus them.

Tests done on the $105 \mathrm{~mm}$ gun firing have showrō that because of the high impulse noise level, firing especially at charge super, must be limited ever $\overrightarrow{\vec{b}}$ with the attenuation afforded by defenders.

The results have been tabulated and are repro duced here from the Interim Defence Standard? $00-27 / 1$ published by the Ministry of Defence. ${ }^{13}$

The two graphs (Figs 2a \& b) show that the recommended limits to impulse noise and the maxi mal limits of exposure (100 impulses fired) are fard below the levels existing with the $105 \mathrm{Fd}$ gun. Pro tection can only be achieved therefore if the num ber of exposures is reduced and greater efficacy is?. achieved in ear defenders. The outcome is the recommendation that at charge super, 10 rounds $/ 24 \mathrm{hr}$ is the maximum exposure during training.

4 Fd Regt RA were designated as artillery sup $\rightarrow$ port to 5 Inf Brigade, to serve in the South Atlantic․ㅡ. By chance, the regiment took only two of its threen batteries (No 29 and 97) the third (No 88) having recently returned from service in Belize. This bat 0 tery remained in the United Kingdom, but while inc 


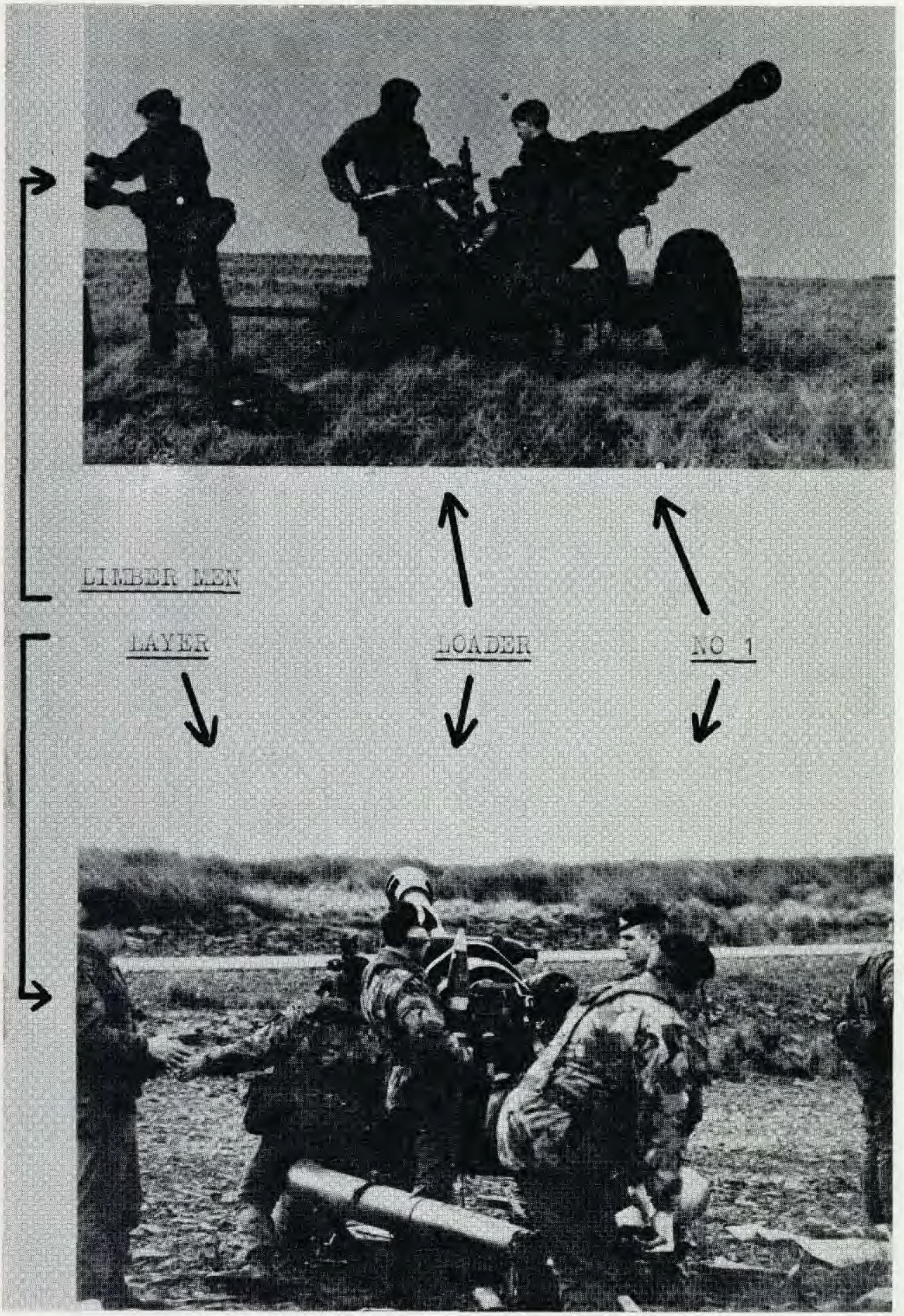

Fig. 1. 105mm Fd Gun Crews

ㄷำ

$\stackrel{\omega}{\rightarrow}$ 음

꼭

오 ญ

(1)

ญำ

एक

○ิ

음

울.

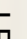




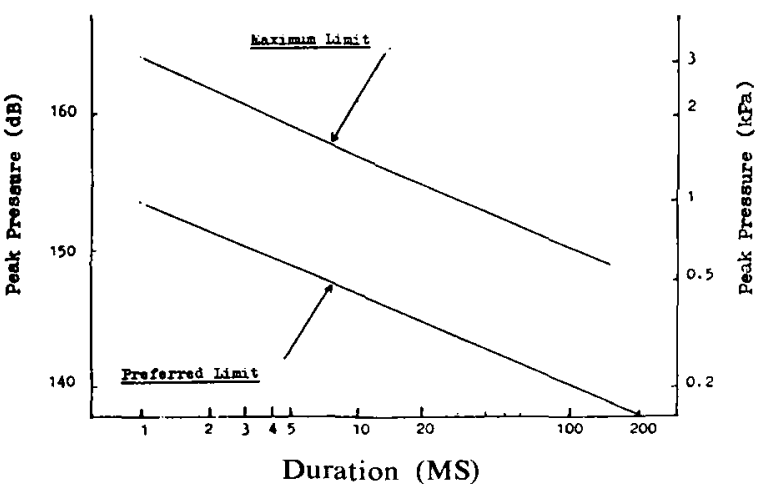

Fig. 2a. Limits for Impulse Noise Exposure Impulses $/ 24$ hours

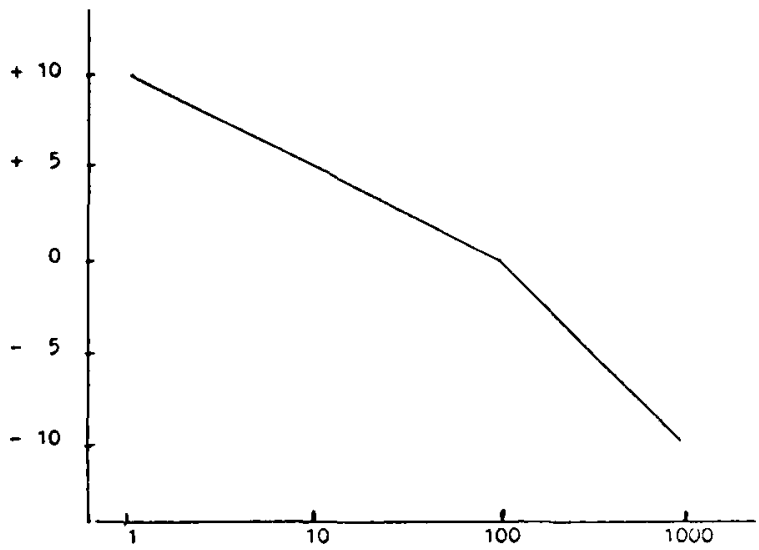

Fig. 2b. Allowances for number of Impulses/24 hours (Reprod.-Interim DEF STAN 00-27/1)

Belize it had fired a large number of rounds in practice under fully protective conditions ${ }^{14}$.

The two batteries who travelled south saw active service throughout the campaign and in the final stages of the assault on Port Stanley, fired up to 1,000 rounds per gun within 5 days. In addition, the personnel had fired their personal weapons in practice, and all were subject to enemy bombardment from air and artillery. Since this noise effect was of unknown timing little aural protection was achieved, but this was not classified as a severe insult to the ear. The high rate of firing also ensured that discipline with regard to ear protection was strained and tested to the limit ${ }^{14}$.

This survey attempts, therefore, to assess any permanent threshold shift caused by this massive assault on the auditory anatomy, exceeding all recommended limits of exposure to such weaponry.

\section{Method}

The survey was carried out after permission haq been given to interview members of 4 th Regimeno Royal Artillery, from its Commanding Officer.

It consisted of three parts:

1. Detailed questioning about exposure events in volving the two batteries who participated in the Falklands War, and the training schedule of the battery who served in Belize. This battery pro $\overrightarrow{\widetilde{\Phi}}$ vided the control group in the survey.

2. A questionnaire.

3. Audiometric testing of subjects and controls. a. Exposure Events. The author found outw from various sources, including interviews with Battery Commanders, soldiers and his owis experience, the length of time the batteries were in action in the Falklands and a reliable assess $\vec{\omega}$ ment of the number of rounds fired in thap time, especially in the days preceding the figan assault. This was used as a check agai $5 \mathrm{sP}$ replies in the questionnaire.

Details of exposure time during practice atd number of rounds fired were obtained about the control battery and this was used as a base line for subsequent assessment of the differe gice in the exposure levels between controls those exposed.

b. Questionnaire. An attempt was made test all soldiers who fired the $105 \mathrm{~mm} \mathrm{Fd}$ in the Falklands and those from the batter who did not go south. Eighty four soldiers wh served in the Falklands and thirty who did nog eventually took part in the survey.

They were asked to fill out the questionnair $\overrightarrow{\vec{E}}$ which was orientated to those who served south. However, the control group were asket to answer any question, not applicable directly: with reference to events of the past year.

Controls and those exposed were matched be age, sex and length of service in the RA, as well as their positions on the gun. Because of Service needs in the Falklands, not all who supplied ammunition to the guns were RA, but were cooks and engineers. However, they. matched as regards age and service and were therefore included.

c. Audiometric Testing. Subjects and controls were randomly allocated reporting times fo examination and audiometry. The rate of $12 / \mathrm{h}$. was achieved as three machines were availables for testing.

The author examined all to be tested, clini cally, to exclude obvious pathology, and he and 
his assistant gave assistance at any query about the questionnaire.

Conditions for audiometry were not optimal, but a good effort to get acceptable quietness was obtained, by notification and location of the testing site in a quiet area. Background noise did not exceed $50 \mathrm{dBA}$ at any time.

After the questionnaire had been completed, each subject was instructed in the test procedure and given a trial.

The audiometer used was the MAICO MA 26 Computer Audiometer allowing automatic testing. Once the author was certain that the subject understood the nature of the test, automatic audiometry was carried out.

In subjects who, because of a variety of reasons, had invalid tests, the procedure was repeated after a period of instruction and this time these subjects were tested on their own, with one of the directing staff supervising.

Where the machine advised masking (see discussion) a repeat audiogram was performed and if the results were compatible with the original, then the original results were accepted. Each machine was programmed to reject any attempt by subjects to anticipate the stimuli.

\section{Results}

General

Originally 130 soldiers of the regiment were detailed for the study. The numbers actually tested were 114 a response rate of $88 \%$ which was very gratifying. The reasons for the remainder not being tested include illness, leave or other Service commitments.

\section{Questionnaire}

This was not comprehensive nor specific to the regiment as it is being used as a basic screening test for a wider survey involving all arms of the Service who were exposed to loud noise levels while serving in the Falklands.

The results are summarised in Table III. The mean ages of both controls and those exposed are well matched as were their lengths of service. Positions on the gun were also well matched and numbers between controls (30) and each battery exposed (42) were acceptable.

All types of issue ear defenders were used as well as others obtained privately and these included one soldier who used the filter tips of a well known brand of cigarettes as defenders! There was a high percentage of defenders used in the control battery when firing and, as expected, considerably lower levels in those batteries who were exposed (Table
Table III

\begin{tabular}{|c|c|c|c|c|c|c|c|}
\hline \multirow[b]{2}{*}{ Centre } & \multirow[b]{2}{*}{ Number } & \multirow{2}{*}{\multicolumn{2}{|c|}{$\begin{array}{l}\text { Age } \\
\text { Mean SD }\end{array}$}} & \multirow{2}{*}{\multicolumn{2}{|c|}{$\begin{array}{l}\text { Service } \\
\text { Mean SD }\end{array}$}} & \multicolumn{2}{|c|}{$\begin{array}{c}\text { Mean } \\
\text { H Grade }\end{array}$} \\
\hline & & & & & & Pre & Post \\
\hline $\begin{array}{l}\text { Control } \\
\text { Exposed }\end{array}$ & 30 & 23.5 & 3.5 & 5.4 & 3.0 & 1.4 & 1.5 \\
\hline $20 \mathrm{~B}+\mathrm{t}$ & 42 & \multirow{2}{*}{\multicolumn{2}{|c|}{$23.4 \quad 4.6$}} & 5.8 & 4.3 & 1.1 & 1.7 \\
\hline 97 Bty & $42)$ & & & 5.3 & 3.3 & 1.2 & 1.9 \\
\hline
\end{tabular}

Table IVa

\% Ear Defence by Batteries

Degree of

Hearing Protection

\begin{tabular}{lcccc} 
Battery & Number & \multicolumn{3}{c}{$\begin{array}{c}\text { Hearing Protection } \\
\text { (Expressed as \% of Nos) }\end{array}$} \\
\cline { 2 - 5 } & & $100 \%$ & Part & $0 \%$ \\
\hline 88 (Control) & 30 & 83 & - & 17 \\
29 & 42 & 62 & 7 & 31 \\
97 & 42 & 38 & 31 & 31 \\
$29 \& 97$ & 84 & 50 & 19 & 31 \\
\hline
\end{tabular}

Table IVb

Post Exposure: Numbers affected related to degree of Ear Protection in 29 \& 97 Btys $n=84$

PULHEEMS

\begin{tabular}{lrrrr}
\hline & PULHEEMS & & \\
& $\mathrm{H} 1$ & $\mathrm{H} 2$ & $\mathrm{H} 3$ & $\mathrm{H} 4$ \\
\hline Always worn & 20 & 17 & 5 & \\
Sometimes worn & 2 & 7 & 5 & \\
Never worn & 12 & 9 & 4 & 1 \\
\hline
\end{tabular}

Table IVc

Hearing Grade of those exposed and who wore Defenders all or most of the time $n=46$

\begin{tabular}{lccc}
\hline & \multicolumn{3}{c}{ Hearing } \\
\cline { 3 - 5 } Defender & H1 & H2 & H3 or above \\
Sonex V5 1 & 9 & 6 & 2 \\
Muffs & 10 & 7 & \\
Others & 4 & 5 & 3 \\
\hline
\end{tabular}

IV). Analysis showed that one battery (97) in fact had a very low level of total use of defenders $(38 \%)$ and this is mirrored in the audiometric results (Table III, last two columns).

\section{Clinical}

Each man was examined before undergoing audiometry and there were no cases found of tympanic membrane damage. Those with wax had it removed and were re-examined and tested 24 hrs later. Few of the subjects admitted to persisting tinnitus but 
a higher proportion admitted to it during the firing events in the south, as was expected.

One subject was excluded because of an active case of otitis media for which he was being treated, and another case was already undergoing investigations for loss of hearing.

\section{Audiogram}

The results of the hearing loss in decibels, at each frequency, were summated into 'low' and 'high' categories eg:

\section{$0.5,1 \& 2 \mathrm{kHz}=$ 'low' \\ $3,4 \& 6 \mathrm{kHz}=$ 'high'}

Each person's ears were tested separately and the results are displayed as histograms in Figs 3 and 4.

As can be seen, the control group has a 'tight' configuration for each ear in the histogram, with no one being lower than $\mathrm{H} 2$ in PULHEEMS category. (Table 1).

Those exposed have a similar pattern, but there is a tail to the right in each histogram with a tota of 17 individuals having a hearing loss of $\mathrm{H} 3$ op worse. In fact one soldier had a summated hearing loss of more than $250 \mathrm{dBA}$ - high range, i one ear!

There were so few pre-Falkland audiograms found in all personnel studied that the only datao available about both groups was their PULHEEM classification. Mean pre and post Falkland gradeş. are given in Table III. Referring to Table I, i $\mathbb{Q}$ will be seen that this may not be a sensitive como parison. There was, however, a degree of shiff. from $\mathrm{H} 1$ to $\mathrm{H} 2$ in more than $50 \%$ of those who served in the Falklands compared with less than $7 \% \overrightarrow{-}$ of the controls. This would indicate some degree of NIHL in most individuals exposed, but they are still within the accepted Pulheems limits so that no restriction on further exposure to gunfire or to thein jobs and promotion need be made.

However, if one charts those exposed by PUL
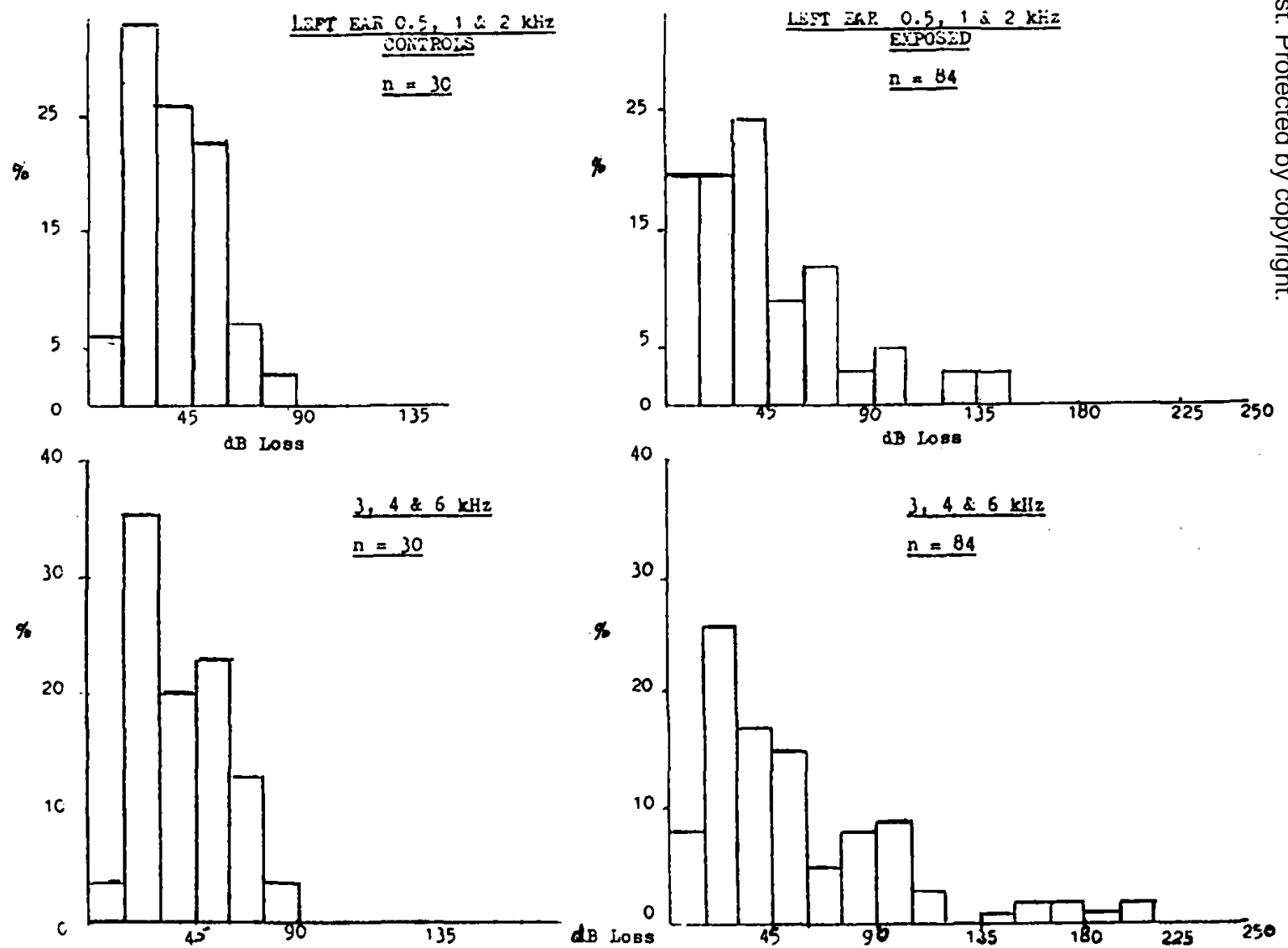

Fig. 3 Histogram showing results of audiometry on exposed and control groups, left ear. 

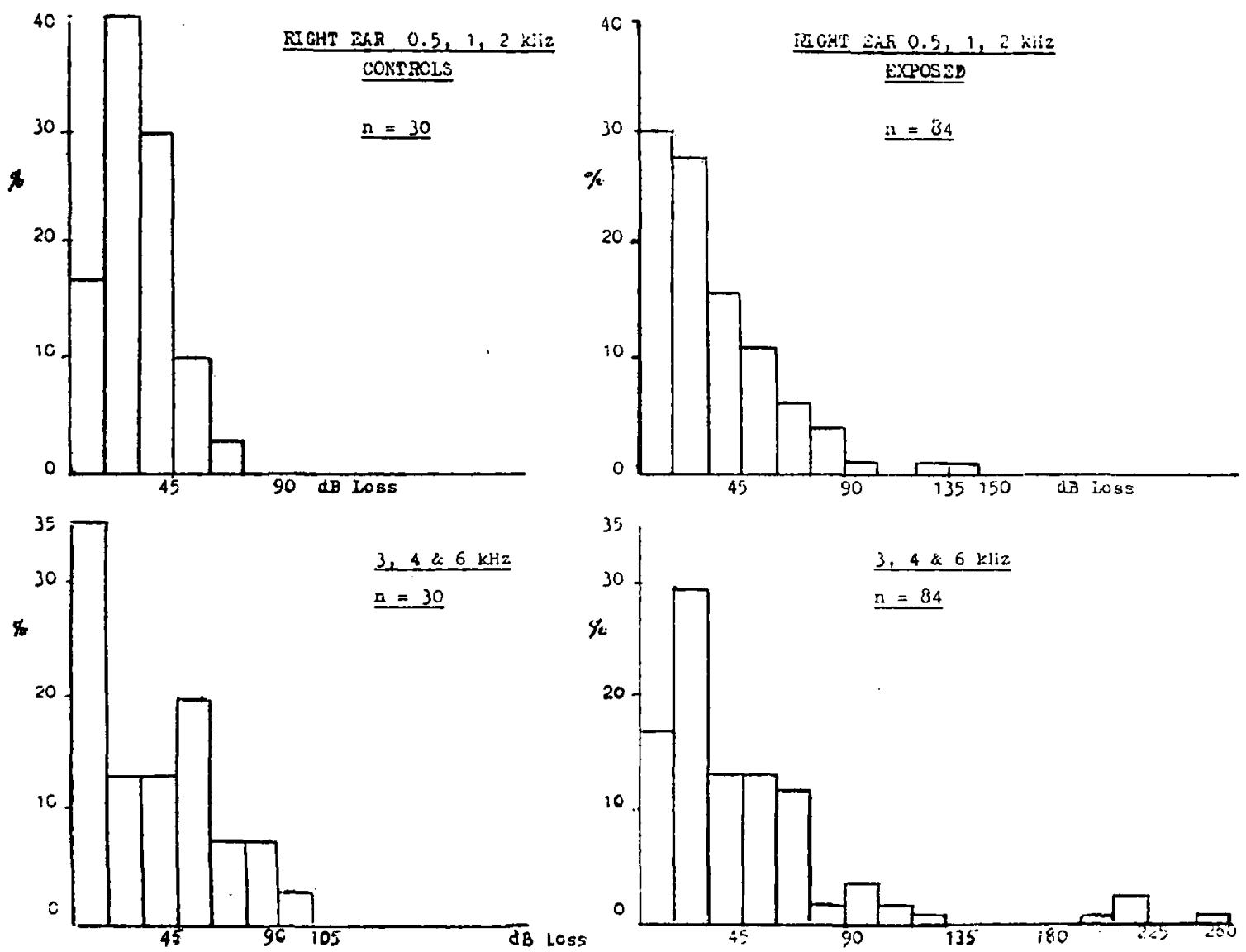

Fig. 4 Histogram showing results of audiometry on exposed and control groups, right ear.

HEEMS grading, accepting $\mathrm{H} 1$ and $\mathrm{H} 2$ as unaffected and $\mathrm{H} 3$ or $\mathrm{H} 4$ as affected, and does the same with the controls, then a chi squared $\left(x^{2}\right)$ test gives $p$ less than .01 for $1 \mathrm{df}$., which is significant. This result, however, is affected by statistical and medical reservations which will be explained in the discussion.

No significant relationship could be found between the degree of protection and the hearing loss sustained (Table IVb) nor is there any significantly greater efficiency of any one type of protector compared with any other (Table IVc).

\section{Discussion}

The aim of the survey was to assess the effect of exposure of artillerymen, with varying degrees of aural protection, to massive impulse noise levels from firing the $105 \mathrm{~mm}$ Field Guns used in "Op Corporate".

Previous studies have been limited ethically, by not exposing volunteers to excessive impulse noise levels. There was no such limitation in this study due to active Service conditions being in operation.

The Army Medical Services have realised that any data from such an exposure will allow modifications to be made to its Hearing Conservation Programme $^{6}$, if necessary, as well as giving an indication of the severity of NIHL suffered in the South Atlantic. This survey is only a small part of a wider one which is hoped will encompass all forces who took part in the land battles of "Op Corporate".

Many facts about NIHL are known and mention must be made of three with reference to the group studied.

Presbyacusis. This factor was not considered due to the youthfulness of the subjects studied.

Imbalanced Hearing Loss is well associated with $\mathcal{N}$ gunfire, and the group studied were no exception. N Many showed imbalance of more than $40 \mathrm{dBA} N$ between ears, a difference picked up by the audio- 
meter read out, with masking suggested. However, this was not done as the survey was performed to get an idea of the severity of the problem, with more accurate individual quantitative testing being left to a later date.

Barotrauma. Brasher ${ }^{4}$ has shown that the effects of barotrauma can range from a Temporary Threshold Shift of hearing with associated tinnitus to a severe and permanent loss possibly due to rupture of the round or oval window. Part of the questionnaire attempted to find out the subjective awareness of such trauma. However, one of the main problems of any questionnaire is the subjective response of opinion, judgement and fact, all of which must be treated as factual by the examiner. Accepting this, there appeared to be little permanent traumatic effect and transient tinnitus was the most common symptom admitted.

The subjective responses to the questionnaire have already been stated and where possible they were checked with actual facts. Accuracy was noted in the types of defenders worn and amount of shellfire the subjects were exposed to. It is obvious that during the campaign the unannounced exposure of impulse noise due to enemy air attack or shellfire did not allow time to carry out protective drills as would be the case in peacetime. This could explain the drop in numbers who admitted wearing defenders $100 \%$ of the time, between the controls and those exposed. The severity of this exposure, compared with that of the field gun being fired, cannot be classified as great.

It was feared that due to the immensity of the exposure, large numbers of soldiers could have had a significant hearing loss, especially as previous studies by Brasher ${ }^{4}$ and Coombe ${ }^{15}$ had shown that as many as $50 \%$ of all individuals can be sensitive to impulse noise. The results, therefore, are gratifying in that the large majority of those tested and exposed are still within the acceptable limits of $\mathrm{H} 1$ and $\mathrm{H}_{2}$ and no restrictions need be placed on their employment.

However, 17 of those exposed were found to be $\mathrm{H} 3$ or worse. Attempts at correlating degree of protection with severity of hearing loss and type of defender worn were of no significance. This is not surprising as the degree of reliability about this part of the questionnaire is low and consequently any significant results must be treated with a great deal of suspicion.

Table II shows the attenuation properties of the three main types of defender issued to the Army. It will be seen that the muffs offer the greatest degree of protection and so those who wore them could be expected to suffer the least. The results (Fig 5c) using those who admitted wearing defenders all or most of the time, (n 46) in fact show there is little difference between the insert, Sonex V51 and the muff. One explanation could be the added protection given to the insert wearers by placing the fingers over the meati, and this could equate to the protection given by muffs.

Accepting the 17 who had an $\mathrm{H} 3$ or $\mathrm{H} 4$ grading as being affected, then the chi-squared test does show a significant change, but the factors listed below could have influenced this finding.

a. The audiometry was a single test, thus accuracy of hearing levels were not confirmed. Repeat audiometry was performed to confirm levels where masking was suggested.

b. Bias could have been introduced due to testing outside sound-proof booths although background noise level was not excessive.

c. No masking was carried out on subjects who had an inter-aural imbalance of more than $40 \mathrm{dBA}$ and this of course could increase the severity the summated hearing loss.

d. Examination of medical records showed that eight out of 114 had pre-Falkland audiometrit records in the F Med 4; and this was insufficier to draw any conclusion over pre and post effect? Subsequently comparison was done using the PULHEEMS $\mathrm{H}$ grading but this was insensitive te minor differences and minimised any actuad changes in category.

e. Statistically the numbers are very small and therefore the degree of reliability in the statistical test as being truly representative of the total exposed population must be questioned. However, the exposed sample was well matched as regards age, service and job so that any change must have some significance.

In conclusion, this survey has shown that despite the exposure to very high levels of assorted impulse noises, the problem is not as bad as was feared. There are numbers who have had a permanent threshold shift and who will have to be investigated further. However, the large majority have either been unaffected, or within the criteria used, have had minimal changes. This may have been through good ear protection, good anticipation or good discipline, 3 but any change seen is not enough to warrant discharge from the Service or restriction of employment, especially in further exposure to gunfire.

As a test of the Army's audiometric programme, the study has indicated the increased attention to hearing conservation and the concern to improve the attenuating properties of ear defenders.

Such attention may be centred in using both types $N$ of defenders, inserts and muffs together, when $N$ exposed to weapons of known noisiness. 
While the audiometric programme shuws good progress with regard to protection, the same rate of progress is not maintained with regard to audiometry of serving soldiers and the availability of audiograms in their medical documents. The problem is large, and progress has been made, but until each soldier has been audiogrammed regularly, comparative assessments of the effects of continued exposure are impossible.

Despite the good results shown in the screening, there is a problem facing the Army Medical Services. There are sufficient numbers grossly affected and these will have to be referred to specialised clinics for accurate assessment and decisions about Service future. If these figures are reflected in the larger survey at present being undertaken, then the Army Medical Services may be faced with a severe administration and logistical problem with regard to screening, assessment and management. As a start, all who served in the Falklands have been designated 'specialised troops' and as such will be audiogrammed again in one year's time for confirmation of hearing grade.

\section{Acknowledgements}

I should like to thank all who helped in this survey and in particular Lt Col T J Bembridge, RA, Col A Harwood, L/RAMC, Cpl Taylor and the typists.

\section{REFERENCES}

1 Waldron H A. Lecture notes on Occupational Medicine (Gd 2) Ch 8 215-223.
2 Aterley G K C and Martin A M. Equivalent্ continuous noise level as a measure of injury from impact and impulse noise, Ann Occup $H y$ 1971; 14: 11-23.

3 LiVesey B. Acoustic trauma as an occupationa\$? hazard in Infantrymen. J R Army Med Corps 1965) 111: $188-193$.

4 BRASher $P F$. Modern Weapons and the human earo $J$ R Army Med Corps 1969; 115: 163-169.

5 Paul, Chai and Thomas. Healing in Military Per $\overline{\bar{F}}$ sonnel. Ann Acad Med Singapore 1979; 8 (2): 164 171.

6 Army Hearing Conservation Programme S/AMD 4/8/2 AMD 5 (RESTRICTED).

7 Health and Safety at Work Act 1974

8 Code of Practice 1972.

9 Health and Safety Commission Consultative Document 1981.

10 Pulheems AJSS of Medical Classification 1976 (JSP 346).

11 New Joint Service Audiometrically Based Hearing Standards (1979) Annex A to D/AMD/4/8/6 AMLP 4 (RESTRICTED).

12 FORREST M R. $105 \mathrm{~mm}$ light gun blast overpr\&ssures-effect on hearing. APRE 301/4/19 dated Oct 1979 (RESTRICTED).

13 Acceptable limits for exposure to impulse noํํ from military weapons. Interim Defence Stand 00-27/1, 22 Feb 1982.

14 Personal Communications, Commanding Offieer officers and other ranks 4 Fd Regt RA, Lille Bts Aldershot.

15 CоOмвE D H. Implication of the Army's Audro metric Screening Pt 1.J R Army Med Corps 19800 126: $25-32$.

\section{AIRBORNE MEDICAL SOCIETY}

1. The society was founded as a clinical meeting group during the last war. Since 1948 it has met annually as a dinner club.

2. Membership is open to all officers who have served in the Airborne Medical Services, regular or volunteer.

3. If your membership has lapsed and you no longer are circulated with dinner details or if you are eligible yet never joined please contact the society at one of the adresses below.

4. Membership of the society costs $£ 2$ annually and the dinner cub meets to coincide with the Calcutta Cup Rugby Match.
Secretary: Lieutenant Colonel S F Macfarlane RADC (V), c/o 144 Field Ambulance (Volunteers Duke of York's Headquarters, London SW3 4SB' 01-930-4466 (Chelsea Military) extension 438.

Treasurer: Major A H M Macmillan RAMC Headquarters 5 Airborne Brigade, Arnhem Bar:racks, Aldershot, Hampshire GU11 2AU. 0252-2443 (Montgomery Mil) extension 411. 